\section{Impacted nail in duodenum: endoscopic removal with a novel magnetic foreign body retriever}

A 2-year-old boy presented with history of vomiting for 7 days. He had esophageal atresia for which he had undergone restorative surgery in early infancy. Abdominal radiography revealed a nail around $5 \mathrm{~cm}$ in length lodged in the duodenum with the head lying proximally (๑ Fig. 1). Upper gastrointestinal endoscopy revealed a smooth stricture at mid esophagus which was dilated to $9 \mathrm{~mm}$ with a wire-guided Savary dilator. The endoscope could be negotiated thereafter and a nail was seen impacted in the duodenal bulb. The endoscope could not be passed into the duodenum because of the impacted nail. The endoscope was removed and reintroduced after a magnetic retrieval instrument had been attached to its tip ( $\odot$ Fig. 2) [1,2]. Once the endoscope reached the antrum, the magnet was advanced further into the duodenal bulb under fluoroscopic guidance. The nail head stuck to the magnet immediately. The endoscope was then withdrawn up to the esophagus, where the nail disengaged from the magnet. The endoscope was taken out and the magnetic retrieval instrument removed. The endoscope was then reintroduced, the head of the nail was held with a snare, and the nail was retrieved with the sharp end trailing.

Endoscopic removal of sharp objects using an overtube or hood has been reported, but in this case no overtube or hood could be used because of the tight esophageal stricture $[3,4]$. Failure to introduce the endoscope into the duodenum made other endoscopic accessories (snare and rat-tooth forceps) useless. There was a fear of disengaging the foreign body at the pharynx in the absence of an overtube, and for this reason a snare was used to avoid such a situation. Fluoroscopy helped in guiding the magnetic retriever to the foreign body, and the proximal location of the nail head with its larger surface area made it easier

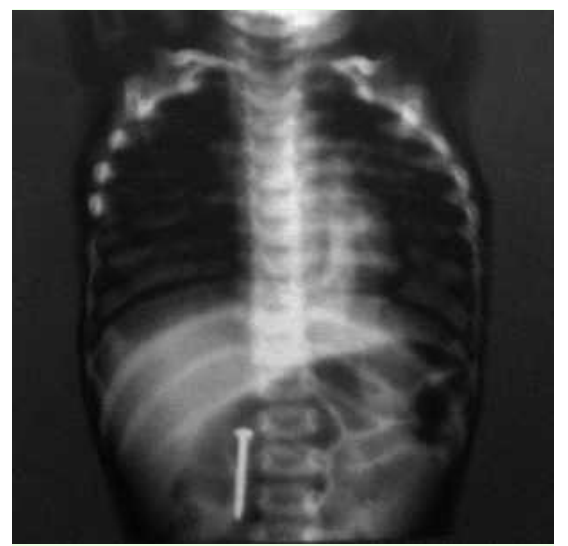

Fig. 1 Abdominal radiograph revealing impacted nail in duodenum.

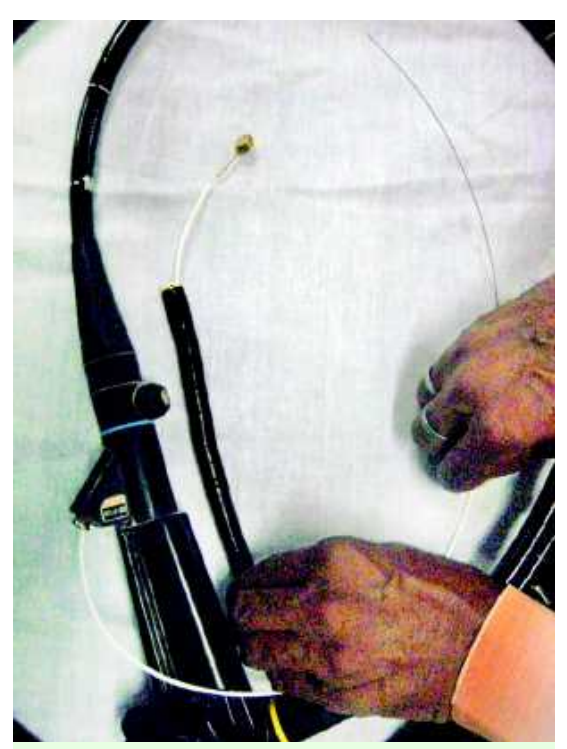

Fig. 2 Upper gastrointestinal endoscope with attached magnetic foreign body retriever.

to get the head of the nail attached to the magnet first. Removal of sharp objects without the use of any protective hood or overtube under fluoroscopic guidance with the help of a magnetic retrieval instrument has not been reported before.
Endoscopy_UCTN_Code_TTT_1AO_2AL

\section{S. Nijhawan, S. Kumpawat, P. Ashdhir,} N. Behl, A. Jha, R. R. Rai

Department of Gastroenterology, SMS

Medical College, Jaipur, India

\section{References}

1 Nijhawan S, Joshi A, Shende A et al. Endoscopy-assisted ferromagnetic foreign-body removal with a novel magnetic instrument. Endoscopy 2004; 36: 1130

2 Nijhawan S, Singh V, Mallikaarjun Pet al. Endoscopic removal of sharp metallic foreign bodies. Endoscopy 2007; 39 (Suppl. 1): E331

3 Bertoni $G$, Sassatelli $R$, Conigliaro $R$ et al. A simple latex protector hood for safe endoscopic removal of sharp-pointed gastroesophageal foreign bodies. Gastrointest Endosc 1996; 44: 458 - 461

4 Paulson EK, Jaffe RB. Metallic foreign bodies in the stomach: fluoroscopic removal with a magnetic orogastric tube. Radiology 1990; 174: $191-194$

\section{Bibliography}

DOI 10.1055/s-0028-1103469

Endoscopy 2009; 41: E62

(c) Georg Thieme Verlag KG Stuttgart · New York . ISSN 0013-726X

\section{Corresponding author}

\section{S. Nihawan, MD}

Department of Gastroenterology

SMS Medical College

Jaipur

India

Fax: + 91-141-2560994

Dr_nijhawan@yahoo.com 